Article

\title{
Performance and Reinforcement Mechanism of Modified Asphalt Binders with Nano-Particles, Whiskers, and Fibers
}

\author{
Xiangyang Xing ${ }^{1}$, Jianzhong Pei ${ }^{1}$, Chenchen Shen ${ }^{1}$, Rui Li ${ }^{1, *} \mathbb{0}$, Jiupeng Zhang ${ }^{1}$, \\ Jianyou Huang ${ }^{1}$ and Dongliang $\mathrm{Hu}^{2}$ \\ 1 School of Highway, Chang'an University, Xi'an 710064, Shaanxi, China \\ 2 School of Transportation, Southeast University, Nanjing 211189, Jiangsu, China \\ * Correspondence: lirui@chd.edu.cn; Tel.: +86-029-823-34296
}

Received: 10 June 2019; Accepted: 22 July 2019; Published: 26 July 2019

check for updates

\begin{abstract}
The asphalt binders could be modified to improve road perfo rmances by using various methods, and the reinforcement mechanisms are obviously different and quietly affect the road performances. According to the composite reinforcement theory, nano- $\mathrm{CaCO}_{3}$ particles, $\mathrm{CaCO}_{3}$ whiskers, and aramid fibers were used as reinforcements to prepare modified asphalt binders, and the conventional technical performances and dynamic shear rheometer (DSR) rheological properties were measured and investigated. In addition, scanning electron microscopy (SEM) was applied to observe the interfaces between reinforcements and asphalt matrixes and the different reinforcement mechanisms were analyzed. The test results showed that the use of nano- $\mathrm{CaCO}_{3}$ particles, $\mathrm{CaCO}_{3}$ whiskers, and aramid fibers can improve the high-temperature stability of modified asphalt binders by different reinforcement mechanisms. The nano- $\mathrm{CaCO}_{3}$ particles were still effective under high-temperature conditions and could last for a long time through the principle of dispersion enhancement. The $\mathrm{CaCO}_{3}$ whiskers segregate easily and cannot be well dispersed in asphalt binders. The aramid fibers played an important role of stress transmission and fiber reinforcement in asphalt binders, and $2 \mathrm{~mm}$-aramid fibers hold the best reinforcement effects. The conclusions can provide a reference for the selection and application of modifiers in the preparation of modified asphalt in laboratory and engineering projects.
\end{abstract}

Keywords: modified asphalt binder; road performance; reinforcement mechanism; nano- $\mathrm{CaCO}_{3}$ particles; $\mathrm{CaCO}_{3}$ whiskers; aramid fibers

\section{Introduction}

Adding various modifiers with excellent performance and moderate price in asphalt is an effective method to enhance asphalt performance. The modifiers refer to the natural, synthetic organic, or inorganic materials added to asphalt binder, including fibers, resin, high-molecular polymer, natural asphalt, ground rubber powder, or other materials, which can be melted and dispersed in asphalt binder to improve the performance of asphalt mixture pavement [1-6].

At present, modified asphalt has made great progress, and products with excellent properties such as styrene-butadienestyrene (SBS) and styrene butadiene rubber (SBR) polymer modifier are widely used. With the progress of materials science and the improvement of experimental conditions, new materials were used as modifiers to prepare new modified asphalt binders. In terms of physical modification methods, nano- $\mathrm{CaCO}_{3}, \mathrm{CaCO}_{3}$ whiskers, and aramid fibers are the representatives of these emerging modified materials. The three materials have different shapes and belong to nanometers, micrometers, and millimeters, respectively. In this study, these three different scale materials were 
used to prepare modified asphalt in order to explore the effects of different reinforcements on the performance of modified asphalt from the perspective of composite materials.

With the rapid development of nanomaterials, nano- $\mathrm{CaCO}_{3}$ has been used as a stable and inexpensive material to prepare modified asphalt. Ali et al. added nano- $\mathrm{CaCO}_{3}$ to asphalt mixture and the test showed that nano- $\mathrm{CaCO}_{3}$ modified asphalt can improve the high-temperature resistance of rutting and water stability of asphalt mixture, and it is suitable for highway construction in hot and humid areas [7]. Han et al. found that nano- $\mathrm{CaCO}_{3}$ can be uniformly dispersed in SBS-modified asphalt, which can improve the toughness, strength, and thermal stability of modified asphalt [8]. Hamedi et al. found that nano- $\mathrm{CaCO}_{3}$ increased the wettability of asphalt binder to aggregate [9]. Nano- $\mathrm{CaCO}_{3}$ was used by Hao et al. to improve the dynamic stability and high-temperature performance of asphalt concrete AC-13 [10]. You et al. used $2 \%$ and $4 \%$ nano-clay in asphalt binder, and the complex shear modulus of modified asphalt increased by $66 \%$ and $125 \%$, respectively [11]. The above studies showed that nano- $\mathrm{CaCO}_{3}$ as a reinforcement can improve the high-temperature performance of asphalt mixtures.

Whiskers are high-purity fibrous single crystals and they have excellent mechanical and physical properties due to its nearly complete crystal structure. Whiskers have been widely used in environmentally friendly coatings, building materials, and other fields [12-17]. Zhang et al. found that $\mathrm{CaCO}_{3}$ whiskers can improve the high-temperature stability in high-modulus asphalt mixture [18]. Yang et al. studied hybrid fibers containing polyester fibers and $\mathrm{CaCO}_{3}$ whiskers to improve the toughness and mechanical properties of cement slurries [19]. Cao et al. applied various mixed $\mathrm{CaCO}_{3}$ whiskers added to cement concrete and found that $\mathrm{CaCO}_{3}$ whiskers had crack resistance in cement concrete [20,21]. Cai et al. incorporated polyvinyl alcohol (PVA) fibers and $\mathrm{CaCO}_{3}$ whiskers into multi-scale engineered cementitious composite (MS-ECC). The results showed that the ductility of MS-ECC could be improved by the appropriate addition of $\mathrm{CaCO}_{3}$ whiskers [22]. Xing et al. found that $\mathrm{CaCO}_{3}$ whiskers could improve the high-temperature performance of asphalt [23]. Li et al. showed that $\mathrm{CaCO}_{3}$ whiskers could effectively improve the strength of oil well cement [24].

Compared with other organic fibers, aramid fibers have advantages in tensile strength and high temperature resistance, but there are limited studies on modified asphalt with chopped aramid fibers. Klinsky et al. used polypropylene and aramid fibers in hot mix asphalt and found that fiber improved the performance of asphalt pavement and reduced the occurrence of rutting, looseness, fatigue, and fracture [25]. Fazaeli et al. found that the simultaneous use of polyolefin-aramid fibers and Sasobit in asphalt mixtures improved the durability of the asphalt mixture and improved the mixing of the asphalt mixture, which would reduce implementation costs and extend the life of asphalt pavement [26]. Mirabdolazimi et al. found that adding suitable polymer fibers to hot mix asphalt improved the dynamic properties of asphalt mixes [27]. Piotr Jaskuła et al. evaluated the low temperature cracking susceptibility through a bending test of rectangular beams and a semi-circular bending test based on fracture mechanics theory. The results showed that the use of aramid fibers improved the low-temperature performance of asphalt pavement [28]. Hung et al. pointed out that aramid fibers generally exhibit higher tensile strength and modulus than aliphatic fibers [29]. Badeli et al. found that Aramid Pulp Fiber (APF) had very high tensile strength, modulus, and high cohesion, which effectively improved the fatigue life of asphalt mixture [30]. Eskandarsefat et al. showed that Poly-functional fibers significantly improved the softening point and viscosity of asphalt by a conventional asphalt performance test and rheological tests [31].

However, facing the emerging new materials, the selection of modifiers is still relatively blind, mostly relying on the macroscopic properties of modified asphalt binders. In addition, the research on the modification mechanism of modified asphalt and the comparison of the modification mechanisms of different modifiers are less clear. In this study, the properties and mechanisms of modified asphalt are explored from the perspective of composite materials. The modifier acts as a reinforcement and the base asphalt acts as a matrix. For the modifier selection, it is very meaningful to study the effects of different scale reinforcements on modified asphalt and to explore their modification mechanisms. 
In this study, the same dosage ( $2 \mathrm{wt} \%$ of asphalt) of modifiers were used to prepare modified asphalt binders. The penetration, softening point, and ductility of aramid fibers-, $\mathrm{CaCO}_{3}$ whiskers-, and nano- $\mathrm{CaCO}_{3}$ particles-modified asphalt was tested. The rheological properties of three modified asphalt binders were analyzed by dynamic shear rheometer (DSR). Scanning electron microscopy (SEM) was used to observe the microscopic morphology of three reinforcements. The performance of three different reinforcement-modified asphalt binders was compared and the mechanisms and causes of these differences were discussed.

\section{Material and Methods}

\subsection{Raw Materials}

The SK-90 base asphalt was selected for the preparation of different modified asphalt binders. The basic characteristics are listed in Table 1.

Table 1. Test results of SK-90 base asphalt.

\begin{tabular}{cc}
\hline Test Indices & Measured Values \\
\hline Penetration at $25^{\circ} \mathrm{C}, 0.1 \mathrm{~mm}$ & 89.7 \\
Ductility at $10{ }^{\circ} \mathrm{C}, \mathrm{cm}$ & 61 \\
Softening Point (Ring-and-Ball method), ${ }^{\circ} \mathrm{C}$ & 44.3 \\
\hline
\end{tabular}

Nano- $\mathrm{CaCO}_{3}$ is a white powdery solid. Its average particle size is about $10-100 \mathrm{~nm}$. The calium carbonate content of $\mathrm{Nano}-\mathrm{CaCO}_{3}$ is $98.5 \%$, and its thermal decomposition temperature is about $530{ }^{\circ} \mathrm{C} . \mathrm{CaCO}_{3}$ whiskers are a white fluffy powder with a diameter of $1-3 \mu \mathrm{m}$. The average length is $20-30 \mu \mathrm{m}$. Its density is about $2.8 \mathrm{~g} / \mathrm{cm}^{3}$. Aramid fiber is a new type of high-tech synthetic fiber with many excellent properties. It is often used as a reinforcing material to make high-performance composite materials. In this study, the length of aramid fibers is $2 \mathrm{~mm}$. The basic characteristics of nano- $\mathrm{CaCO}_{3}, \mathrm{CaCO}_{3}$ whiskers, and aramid fibers are summarized in Tables 2-4. The appearance of the three materials are shown in Figure 1.

Table 2. Characteristics of nano- $\mathrm{CaCO}_{3}$.

\begin{tabular}{cccccc}
\hline Appearance & $\begin{array}{c}\text { Average } \\
\text { Particle Size } \\
(\mathbf{n m})\end{array}$ & $\begin{array}{c}\text { Calcium Carbonate } \\
\text { Content }(\mathbf{\%})\end{array}$ & $\begin{array}{c}\text { Whiteness } \\
(\%)\end{array}$ & $\begin{array}{c}\text { Moisture } \\
\text { Content }(\%)\end{array}$ & $\begin{array}{c}\text { Decomposition } \\
\text { Temperature } \\
\left({ }^{\circ} \mathbf{C}\right)\end{array}$ \\
\hline White powder & $10-100$ & 98.5 & 95 & 0.15 & 530 \\
\hline
\end{tabular}

Table 3. Characteristics of $\mathrm{CaCO}_{3}$ whiskers.

\begin{tabular}{cccccc}
\hline Diameter $(\mu \mathrm{m})$ & $\begin{array}{c}\text { Tensile Strength } \\
(\mathbf{M P a})\end{array}$ & $\begin{array}{c}\text { Decomposition } \\
\text { Temperature }\left({ }^{\circ} \mathbf{C}\right)\end{array}$ & $\begin{array}{c}\text { Density } \\
\left(\mathrm{g} / \mathrm{cm}^{3}\right)\end{array}$ & $\begin{array}{c}\text { Average } \\
\text { Length }(\boldsymbol{\mu m})\end{array}$ & $\begin{array}{c}\text { Length-Diameter } \\
\text { Ratio }\end{array}$ \\
\hline $1-3$ & $3000-6000$ & 660 & 2.8 & $20-30$ & $15-60$ \\
\hline
\end{tabular}

Table 4. Characteristics of aramid fibers.

\begin{tabular}{|c|c|c|c|c|c|}
\hline Diameter $(\mu \mathrm{m})$ & $\begin{array}{l}\text { Specific Gravity } \\
\qquad\left(\mathrm{g} / \mathrm{cm}^{3}\right)\end{array}$ & $\begin{array}{c}\text { Elastic } \\
\text { Modulus } \\
\left(\mathrm{cN} \cdot \mathrm{dtex}^{-1}\right)\end{array}$ & $\begin{array}{c}\text { Decomposition } \\
\text { Temperature } \\
\left({ }^{\circ} \mathrm{C}\right)\end{array}$ & $\begin{array}{c}\text { Breaking } \\
\text { Elongation (\%) }\end{array}$ & $\begin{array}{c}\text { Fracture Stress } \\
\text { (GPa) }\end{array}$ \\
\hline $3-5$ & 1.44 & $410-710$ & $430-550$ & 3.6 & 2.76 \\
\hline
\end{tabular}




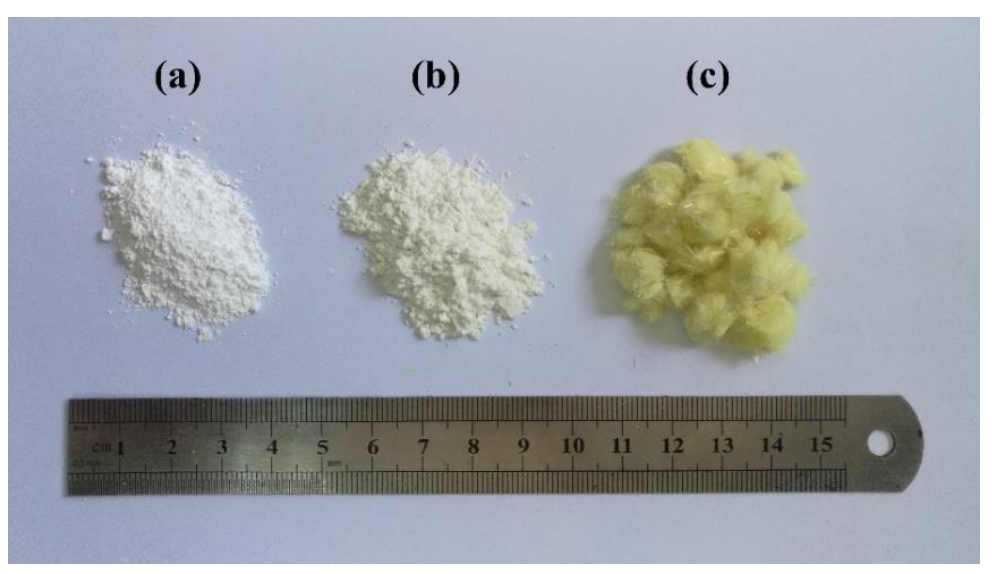

Figure 1. Appearance of different reinforcements. (a) Nano- $\mathrm{CaCO}_{3}$ particles, (b) $\mathrm{CaCO}_{3}$ whiskers, (c) 2 mm-aramid fibers.

\subsection{Preparation of Different Reinforcement-Modified Asphalt Binders}

The preparation process of the modified asphalt binders proposed in this paper is as follows:

(1) Asphalt was placed in an oven, heated to $150^{\circ} \mathrm{C}$, and placed in an electronic balance to weigh $200 \mathrm{~g}$ in a stainless-steel beaker.

(2) The beaker containing the asphalt sample was placed in a constant temperature oil bath at $150{ }^{\circ} \mathrm{C}$.

(3) $4 \mathrm{~g}$ reinforcement was weighed with an electronic balance (2 $\mathrm{wt} \%$ of asphalt sample).

(4) The electric mixer was opened and the stirring speed was set to $350 \mathrm{rpm}$. The above-mentioned weighed reinforcement was gradually added to the asphalt. Stirring was continued until the reinforcement was evenly dispersed.

The general preparation process is shown in Figure 2.

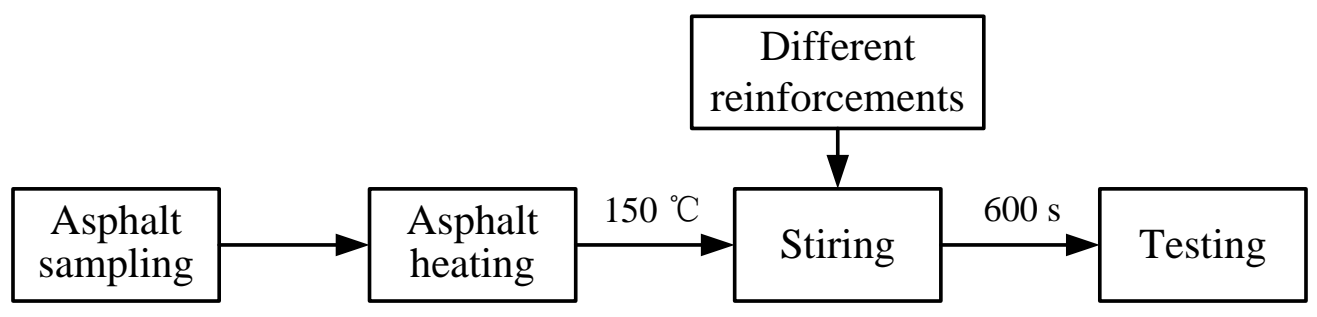

Figure 2. Modified asphalt preparation process.

\subsection{Experiment Methods and Evaluation Indexes}

\subsubsection{Conventional Indicator Tests}

According to the Standard Test Methods of Bitumen and Bituminous Mixtures for Highway Engineering (JTG E20-2011) T0604, T0605, and T0606, the asphalt binders modified with different reinforcements were tested for penetration, softening point, and ductility.

\subsubsection{Dynamic Shear Rheology Test (DSR)}

The temperature scanning mode of DSR is a way to study the dependence of asphalt index on temperature and it can be used to evaluate the high-temperature permanent deformation ability of asphalt. The multiple stress creep recovery (MSCR) test can better reflect the nonlinear viscoelastic response of asphalt, and its indexes have been confirmed to have a good correlation with asphalt pavement performance [32]. The three modified asphalt binders were tested in accordance with the relevant requirements (JTG E20-2011) T 0628-2011 asphalt rheological property test (dynamic shear 
rheometer method). The equipment used was an Anton Paar smartpave 102/H-PTD200 (Anton Paar, Graz, Austria).

\subsubsection{Scanning Electron Microscope (SEM)}

The micromorphology of reinforcements and their morphology in the modified asphalt are important indicators for evaluating the reinforcement performance. In this study, three kinds of reinforcements and three modified asphalt binders prepared with different reinforcements were observed using a ZEISS GeminiSEM 500 (Carl Zeiss AG, Heidenheim, Germany). The parameter settings were: test voltage $20 \mathrm{Kv}$, vacuum degree $1.2 \times 10^{-3} \mathrm{~Pa}$, working distance $10 \mathrm{~mm}$.

\section{Results and Discussion}

\subsection{Conventional Technical Performances of the Modified Asphalt Binders}

It can be seen in Figure 3a that, after the reinforcement addition, the penetration of the three modified asphalt binders decreased to different levels compared to those of base asphalt. Among them, the penetration of $\mathrm{CaCO}_{3}$ whiskers-modified asphalt is 53.5, which is the largest reduction. The penetration value of nano- $\mathrm{CaCO}_{3}$-modified asphalt is 83 , which is the minimum reduction. The aramid fiber-modified asphalt has a penetration value of 80 , which is reduced by $10 \%$. In Figure $3 \mathrm{~b}$, the bar graph is shown for the softening point of different reinforcement-modified asphalt binders under the same dosage conditions. It can be seen that, after adding the reinforcement, the softening points of the three modified asphalt binders increase to different degrees compared to that of base asphalt. The results of $10^{\circ} \mathrm{C}$ ductility of different reinforcement-modified asphalt binders are shown in Figure 3c. It can be seen that, after adding the reinforcing agent, the ductility of aramid fiber-modified asphalt is slightly increased compared with that of base asphalt, and the ductility of $\mathrm{CaCO}_{3}$ whiskers-modified asphalt has the largest decrease in ductility.
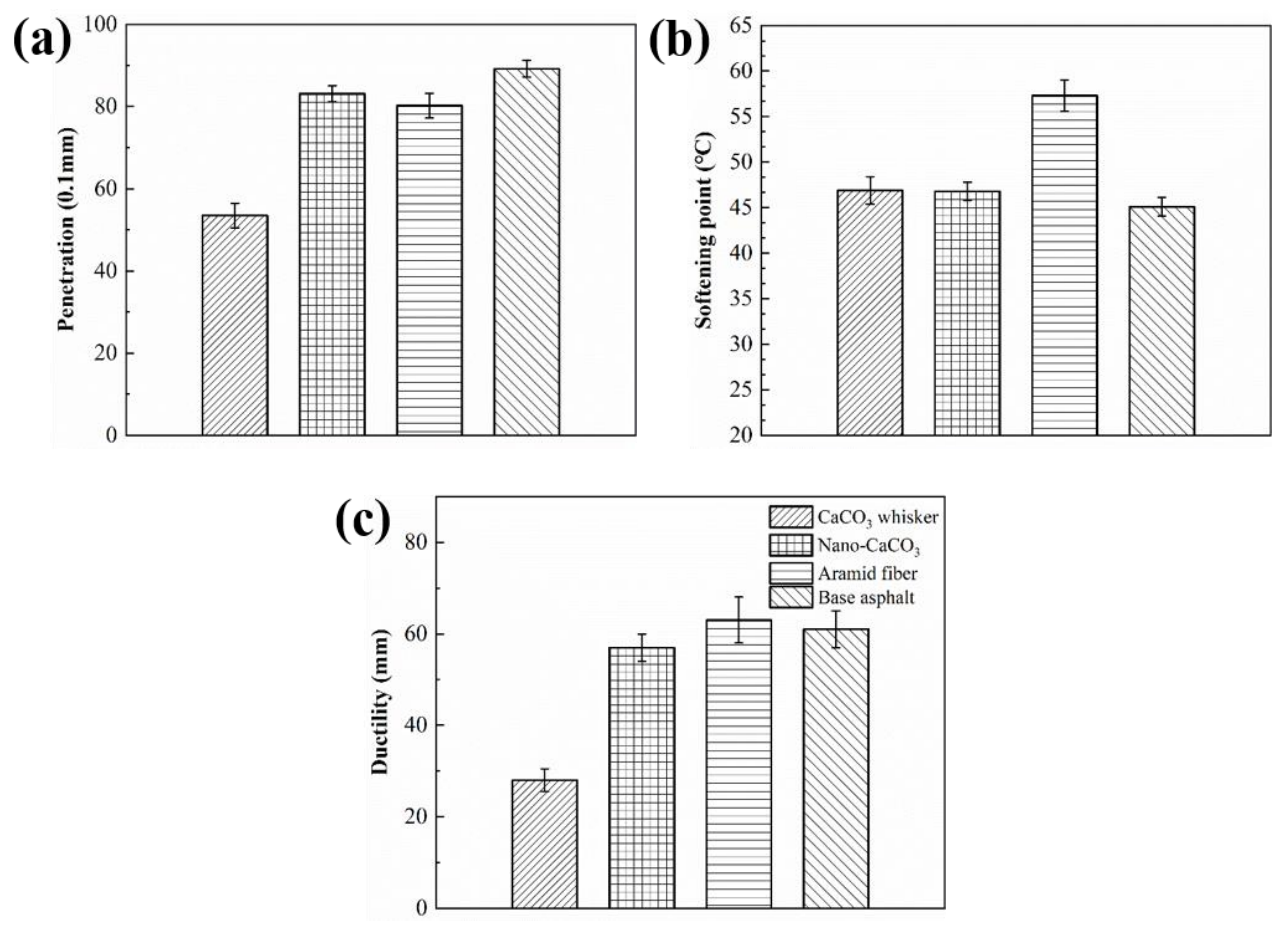

Figure 3. Conventional test results of the modified asphalt binders. (a) Penetration $(0.1 \mathrm{~mm})$, (b) softening point $\left({ }^{\circ} \mathrm{C}\right)$, (c) Ductility $(\mathrm{mm})$. 


\subsection{Rheological Properties of the Modified Asphalt Binders}

\subsubsection{Temperature Sweep Test}

The DSR temperature sweep mode is a study of the temperature dependence of asphalt materials and can be used to evaluate the high-temperature resistance to permanent deformation of asphalt materials. In Figure 4, the rutting factor $\left(\mathrm{G}^{*} / \sin \delta\right)$ are shown for base asphalt, whisker-modified asphalt, nano- $\mathrm{CaCO}_{3}$-modified asphalt, and aramid fiber-modified asphalt over the temperature range of $30-80{ }^{\circ} \mathrm{C}$. It is seen that the rutting factors of modified asphalt binders are greater than that of base asphalt. Among the three modified asphalt binders, the rutting factor of aramid fiber-modified asphalt is slightly higher than that of the whisker-modified asphalt, but the increase is not large. As the temperature increases, the rutting factors of different asphalt binders decrease significantly and tend to reach that of the base asphalt. The reason is that, after the reinforcement is added, the softening point of modified asphalt binders is further improved, and the rutting resistance is enhanced. Under the same dosage, the modification effect of aramid fiber is better than that of other two powder materials.

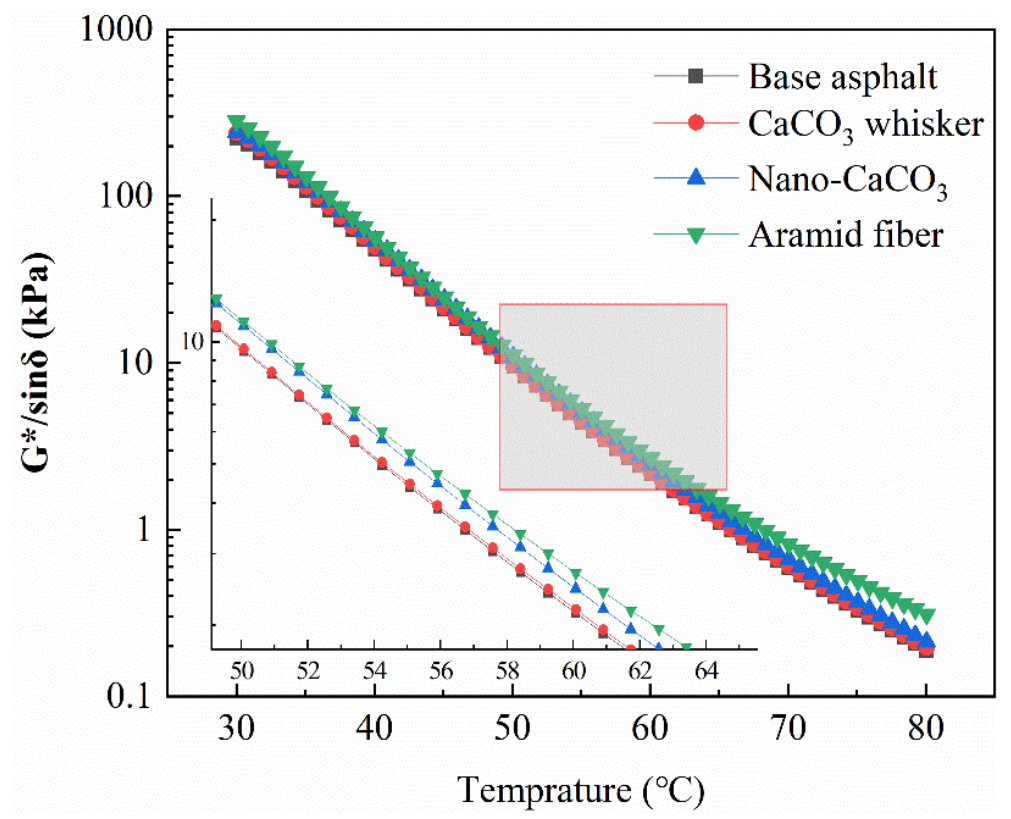

Figure 4. The rutting factors changes of various asphalt binders with temperature.

\subsubsection{Multiple Stress Creep Recovery (MSCR) Test}

To evaluate and compare the stress recovery performance of different reinforcement-modified asphalt, the MSCR under stress conditions of 0.1 and $3.2 \mathrm{kPa}$ was carried out in this study. The test temperature was $64^{\circ} \mathrm{C}$. The experimental results are shown in Figure 5. In Table 5, the average strain recovery rate $(R)$ and the average unrecoverable creep compliance $\left(\mathrm{J}_{\mathrm{nr}}\right)$ are given. As it can be seen in Figure 5, the base asphalt is a temperature-sensitive material. It exhibits more viscous properties under high temperature conditions, the elastic properties are gradually lost and the creep recovery ability is gradually reduced. The three different reinforcement-modified asphalt binders are substantially similar in creep properties to base asphalt. 

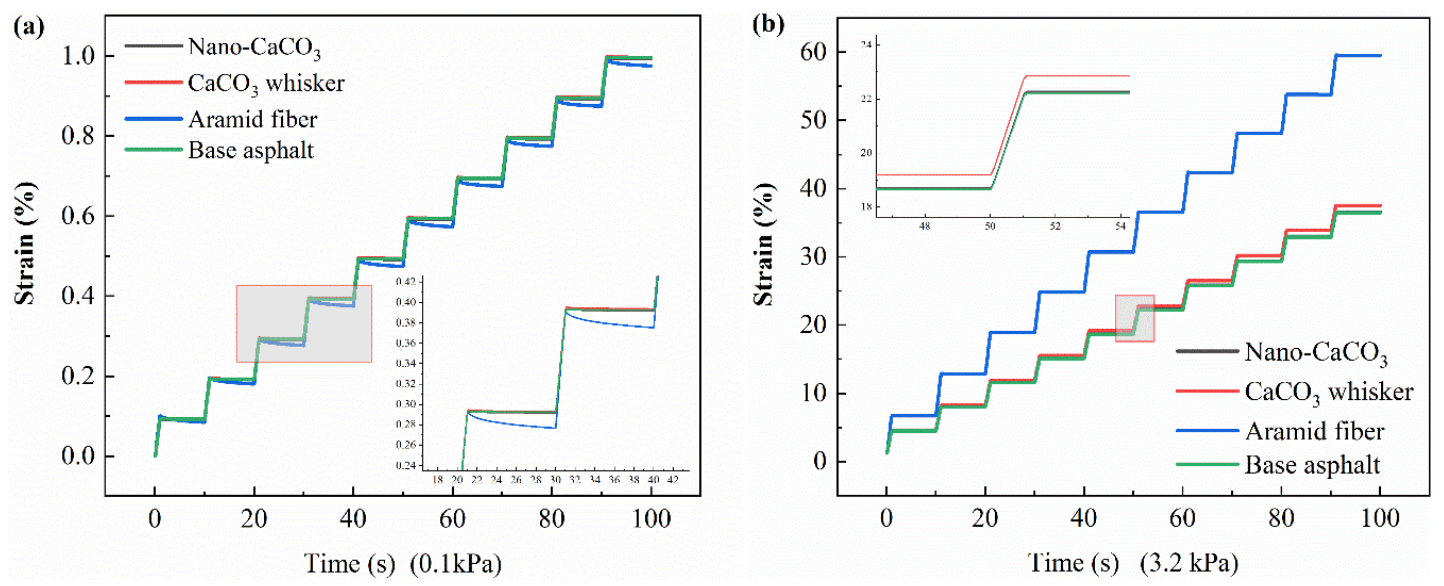

Figure 5. Multiple Stress Creep Recovery (MSCR) curves of modified asphalt binders and base asphalt binder at (a) $0.1 \mathrm{kPa},(\mathbf{b}) 3.2 \mathrm{kPa}$.

Table 5. The calculation results of recovery rate $(\mathrm{R})$ and average unrecoverable creep compliance $\left(\mathrm{J}_{\mathrm{nr}}\right)$.

\begin{tabular}{|c|c|c|c|c|c|c|c|c|}
\hline \multirow{2}{*}{ Asphalt } & \multicolumn{4}{|c|}{$0.1 \mathrm{kPa}$} & \multicolumn{4}{|c|}{$3.2 \mathrm{kPa}$} \\
\hline & $\mathrm{R} / \%$ & Error \% & $\underset{\mathrm{kPa}^{-1}}{\mathrm{Jnr}_{\mathrm{nr}} /}$ & Error \% & $\mathrm{R} / \%$ & Error \% & $\underset{\mathrm{kPa}^{-1}}{\mathrm{Jnr}_{\mathrm{nr}} /}$ & Error \% \\
\hline Nano- $\mathrm{CaCO}_{3}$-modified asphalt & 1.15 & 5.2 & 0.92 & 11.8 & 0.05 & 7.3 & 1.03 & 10.8 \\
\hline $\mathrm{CaCO}_{3}$ whisker-modified asphalt & 2.08 & 3.6 & 0.93 & 12.6 & 0.03 & 6.7 & 1.06 & 13.9 \\
\hline Aramid-modified asphalt & 14.34 & 4.3 & 0.88 & 14.7 & 0.65 & 5.9 & 1.69 & 8.4 \\
\hline Base asphalt & 0.93 & 5.1 & 0.93 & 9.8 & 0.02 & 6.4 & 1.03 & 7.2 \\
\hline
\end{tabular}

Through the calculation of $\mathrm{R}$ and $\mathrm{J}_{\mathrm{nr}}$ for each sample, it is found that each sample still has a certain recovery ability. When the stress level is $0.1 \mathrm{kPa}$, the $\mathrm{R}$ value of aramid fiber-modified asphalt is the largest, and the $\mathrm{R}$ values of $\mathrm{CaCO}_{3}$ whiskers-modified asphalt and nano- $\mathrm{CaCO}_{3}$-modified asphalt are slightly higher than that of base asphalt. The $\mathrm{J}_{\mathrm{nr}}$ of aramid fiber-modified asphalt is the lowest among three kinds of asphalt. The $\mathrm{Jnn}_{\mathrm{nr}}$ values of $\mathrm{CaCO}_{3}$ whiskers-modified asphalt and nano- $\mathrm{CaCO}_{3}$-modified asphalt are basically similar to that of base asphalt. The test results show that, under the low stress level, the strain recovery rate of aramid fiber-modified asphalt is the best, and the unrecoverable creep compliance is the smallest. When the stress level is $3.2 \mathrm{kPa}$, the $\mathrm{R}$ value variation is consistent with that obtained at $0.1 \mathrm{kPa}$. The $\mathrm{Jnn}_{\mathrm{nr}}$ parameter of $\mathrm{CaCO}_{3}$ whiskers-modified asphalt is slightly larger than that of nano- $\mathrm{CaCO}_{3}$-modified asphalt, and the $\mathrm{J}_{\mathrm{nr}}$ parameter of aramid-modified asphalt is larger than those of other three kinds of asphalt. The test results show that the strain recovery rate of aramid fiber-modified asphalt is still the best among several modified asphalt binders after the stress level is increased. At the same time, the unrecoverable creep compliance of aramid fiber-modified asphalt at high stress levels is also increasing.

\subsection{SEM Results of the Reinforcements and Interfaces}

In Figure $6 \mathrm{a}$, it can be observed that the nano- $\mathrm{CaCO}_{3}$ whiskers has a spindle shape, and the crystal shape is large in the middle and small at both ends. The particle size is 10-100 nm, and the aspect ratio is $3-4$, which is basically ellipsoidal. As shown in Figure $6 \mathrm{~b}$, the $\mathrm{CaCO}_{3}$ whiskers have elongated needle shapes. The whiskers selected in the test are hexagonal prisms. If considering the cross-section as approximately circular, the whisker diameters are between $1 \mu \mathrm{m}$ and $3 \mu \mathrm{m}$. At the same time, it can be observed that the whisker lengths are different. The longest whisker can reach more than $100 \mu \mathrm{m}$, and the shortest one is only a few microns. The length-diameter ratio of whiskers is 15-60. It can be observed from Figure $6 \mathrm{c}$ that aramid fibers are bundled and arranged relatively tightly, and the surface is relatively smooth with few adhering substances. 

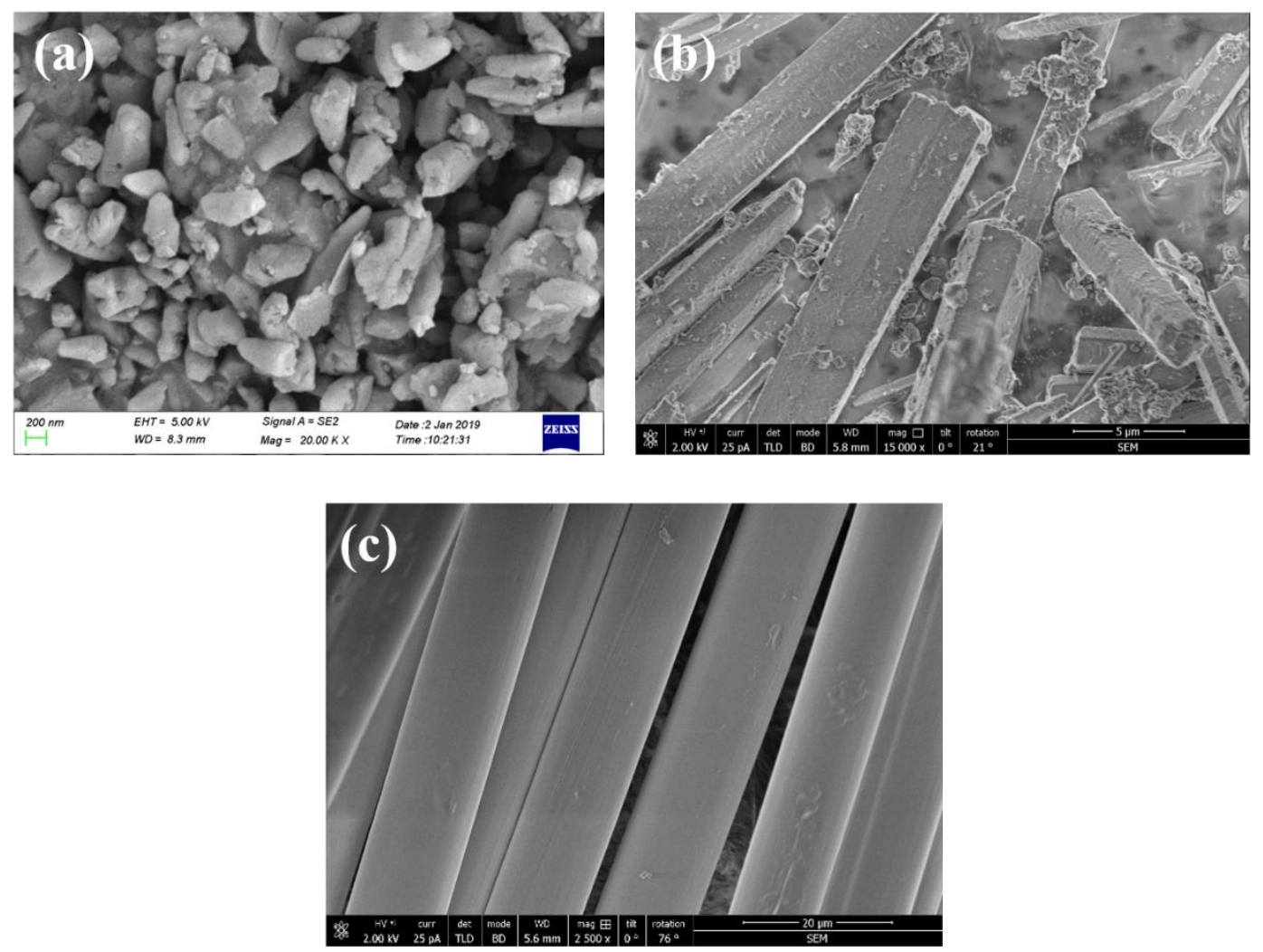

Figure 6. Scanning electron microscopy (SEM) results of nano- $\mathrm{CaCO}_{3}, \mathrm{CaCO}_{3}$ whiskers, and aramid fibers (a) nano- $\mathrm{CaCO}_{3}$, magnification: 20,000×, (b) $\mathrm{CaCO}_{3}$ whiskers, magnification: $15,000 \times$, (c) aramid fibers, magnification: $2500 \times$.

It can be seen in Figure 7 that nano- $\mathrm{CaCO}_{3}$ particles are not dispersed into asphalt as individual particles, and the cohesive particles are relatively obvious. The lumps formed after cohesion are more evenly distributed in the asphalt. As shown in Figure 8, the $\mathrm{CaCO}_{3}$ whiskers are not uniformly dispersed in the asphalt, and there is a phenomenon of agglomeration. Even under vigorous stirring, the $\mathrm{CaCO}_{3}$ whiskers were not sufficiently dispersed in the asphalt, and did not exert the reinforcing effect of the fibers. The reason may be that the density of $\mathrm{CaCO}_{3}$ whiskers and asphalt is very different, and $\mathrm{CaCO}_{3}$ whiskers are precipitated. As shown in Figure 9, the aramid fibers interlaced in the asphalt are spanning the crack and exerting the pull-and-blocking effect.

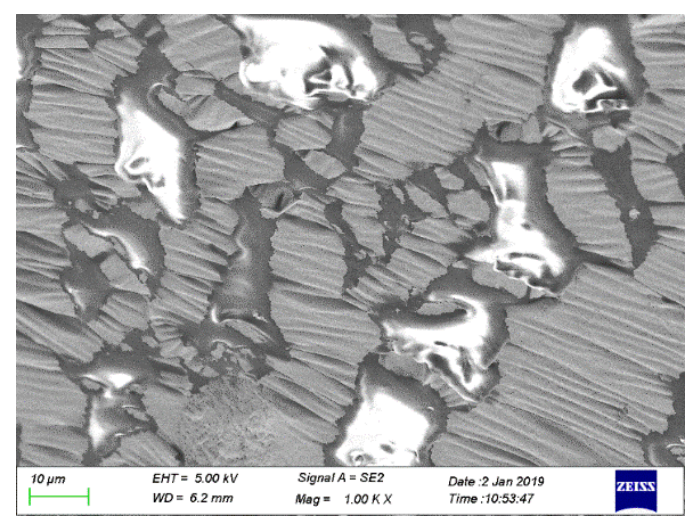

Figure 7. SEM result of nano- $\mathrm{CaCO}_{3}$-modified asphalt (magnification: 1000×). 


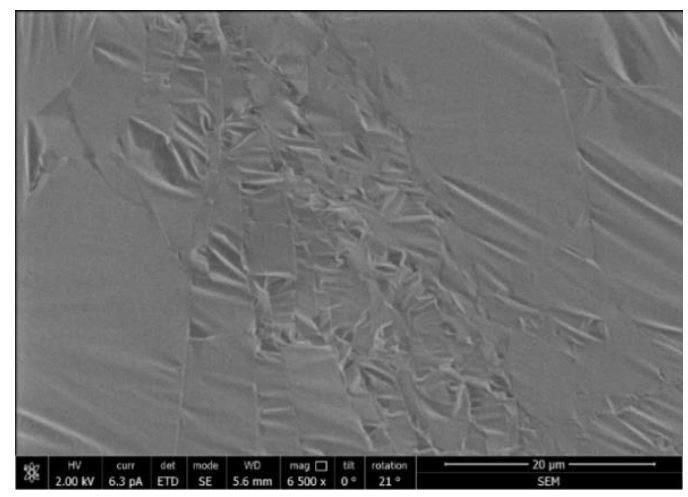

Figure 8. SEM result of $\mathrm{CaCO}_{3}$ whiskers-modified asphalt (magnification: 6500×).
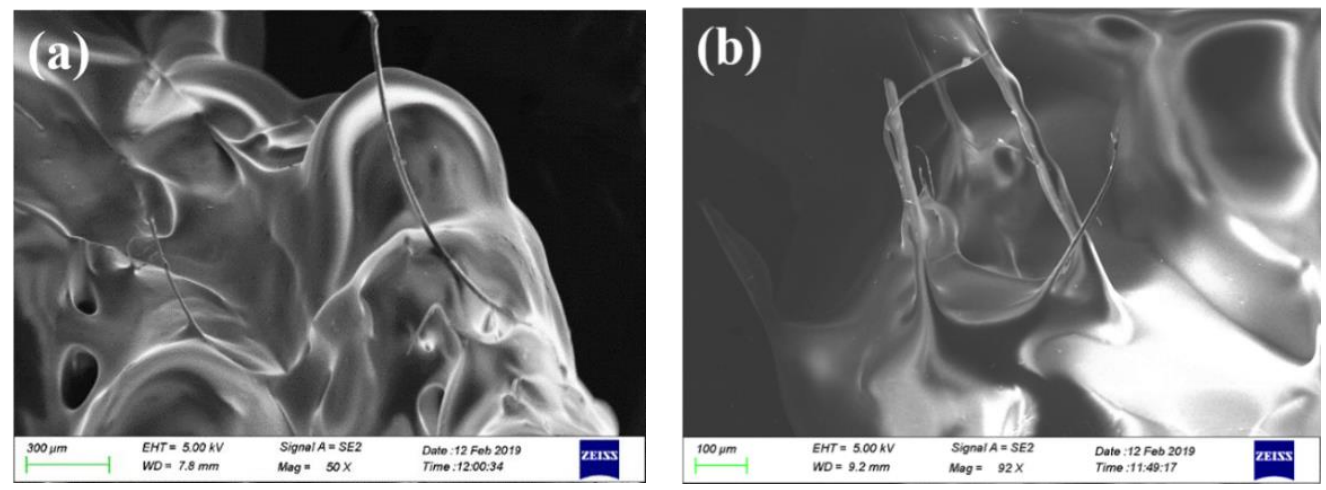

Figure 9. SEM result of aramid fiber-modified asphalt (a) magnification: 50×, (b) magnification: 92×.

\subsection{Reinforcement Mechanisms}

The reinforcement shapes are different, and thus, the reinforcing effect and reinforcing mechanism for the matrix material are also different. In this study, there are three types: diffusion enhancement, whisker enhancement, and fiber reinforcement.

\subsubsection{Reinforcement Mechanism of $\mathrm{Nano}_{-} \mathrm{CaCO}_{3}-$ Modified Asphalt Binder}

The nano- $\mathrm{CaCO}_{3}$ particles are about $10-100 \mathrm{~nm}$ in diameter, and they are dispersed into base asphalt by the heating and stirring method to prepare a modified asphalt. The nano- $\mathrm{CaCO}_{3}$ particles dispersed in the modified asphalt can effectively increase the strength of material that can be explained by the Orowan mechanism and the Hall-Petch reinforcement mechanism. The original idea is to use these small but hard nano- $\mathrm{CaCO}_{3}$ particles to hinder the asphalt binder movement, thereby increasing the modulus of material without significantly affecting the stiffness of the material [33].

The Orowan mechanism theory can be expressed by Equation (1):

$$
\tau=\mu b / L
$$

where, $\tau$ is the yield stress of composite, $\mu$ is the shear modulus of matrix, $b$ is Burgers vector of matrix, and $\mathrm{L}$ is the average distance between the particles.

In this study, according to the Orowan theory, the external load is mainly borne by the asphalt, and nano- $\mathrm{CaCO}_{3}$ particles hinder the dislocation motion of the asphalt, thereby enhancing the properties of the modified asphalt. The smaller the particle size, the smaller the average distance between the particles, and the greater the yield stress of the modified asphalt.

According to the Hall-Petch reinforcement mechanism, the atomic arrangement is irregular at the interface between the nano- $\mathrm{CaCO}_{3}$ particles and asphalt, and the phase interface hinders the plastic deformation of the modified asphalt. 
The Hall-Petch reinforcement mechanism can be expressed by Equation (2):

$$
\sigma=\sigma_{0}+\mathrm{K} \cdot \delta^{-1 / 2}
$$

where, $\sigma$ is the yield strength of the material, which is proportional to the $-1 / 2$ power of the average diameter of the particles. In the case where the particle volume fraction is constant, the smaller the particle size, the more the phase interface, so that the greater the ability to block dislocation motion, and the better the material is strengthened.

In fact, nano- $\mathrm{CaCO}_{3}$ enhances the high-temperature performance of asphalt by diffusion enhancement, which may be the result of the above two mechanisms.

The process of nano- $\mathrm{CaCO}_{3}$-modified asphalt is a physical miscibility process. Due to the extremely small particle size of nano- $\mathrm{CaCO}_{3}$, the miscible system is uniform and stable, and it is suitable for production applications. In this study, nano- $\mathrm{CaCO}_{3}(10-100 \mathrm{~nm})$ was dispersed into the asphalt by heating and stirring. Due to the sufficient thermal stability of nano- $\mathrm{CaCO}_{3}$ under the use temperature conditions, no chemical reaction occurred between the reinforcement and the matrix. Therefore, it does not dissolve in the asphalt and can last for a long time to enhance the effect.

\subsubsection{Reinforcement Mechanism of $\mathrm{CaCO}_{3}$ Whiskers-Modified Asphalt Binder}

The mechanism of whisker-reinforced asphalt is similar to the mechanism of particle-reinforced composites. It is the use of high-strength fibrous whiskers as reinforcements to form composites with higher strength than asphalt, which improves the high-temperature properties of materials, but reduces the plasticity and toughness.

The particle-reinforced composite material is composed of hard particles with the size of 1 to $50 \mu \mathrm{m}$ and the matrix. In particle-reinforced composites, the particles can bear a part of the load, but the load is mainly carried by the matrix. The particles are constrained by the deformation of the matrix to achieve the purpose of reinforcement. The greater the ability of the particles to prevent the dislocation motion in the matrix, the better the enhancement effect [34].

The $\mathrm{CaCO}_{3}$ whiskers are inorganic and do not dissolve in the asphalt, so they can exist in the form of a dispersed phase. The $\mathrm{CaCO}_{3}$ whiskers have no effect on the chemical nature of the asphalt component and its role is equivalent to asphaltenes. As the matrix, the rheological properties of asphalt are changed with the asphaltene content. When adding $\mathrm{CaCO}_{3}$ whiskers to asphalt, the rheological properties of asphalt can be significantly improved, thereby improving the softening point and reducing the penetration of the asphalt.

\subsubsection{Reinforcement Mechanism of Aramid Fibers-Modified Asphalt Binder}

Asphalt is a typical viscoelastic material with a strong temperature sensitivity. The fibers with high tensile strength and modulus were incorporated into asphalt that increased the rutting resistance and the deformability of asphalt, making it more tough.

In this study, the strength and modulus of aramid fibers as a reinforcement were much larger than those of asphalt. On the one hand, the anti-rutting ability of asphalt was improved. The aramid fibers have a lower density than those of nano- $\mathrm{CaCO}_{3}$ and $\mathrm{CaCO}_{3}$ whiskers, and so, they can be uniformly dispersed in asphalt to form a three-dimensional network structure. At the same time, due to the high tensile strength and modulus of aramid fibers, the deformation recovery ability of the asphalt was improved. 


\section{Conclusions}

From the above research we can get the following conclusions:

(1) The reinforcements with the same amount have different reinforcing effects on the composite due to different morphology. The nano- $\mathrm{CaCO}_{3}$ particles, $\mathrm{CaCO}_{3}$ whiskers, and aramid fibers could improve the high-temperature performance of asphalt, but the reinforcement mechanisms were different.

(2) The nano- $\mathrm{CaCO}_{3}$ particles improved the high-temperature performance of asphalt through the diffusion-enhancing mechanism.

(3) The mechanism of $\mathrm{CaCO}_{3}$ whiskers-reinforced asphalt is more similar to the mechanism of particle-reinforced composites. The $\mathrm{CaCO}_{3}$ whiskers improved the high-temperature performance of asphalt, but reduced plasticity and toughness. In addition, since the $\mathrm{CaCO}_{3}$ whiskers themselves are highly dense, they are easily cohesive and precipitated, and thus the prepared modified asphalt has poor stability.

(4) The aramid fibers fully exert the reinforcing and toughening fiber effect in asphalt and have the best modification effect.

Author Contributions: Conceptualization, J.P. and R.L.; Formal analysis, C.S.; Methodology, X.X., J.H. and D.H.; Supervision, J.Z.; Validation, X.X.; Writing-original draft, X.X.; Writing—review \& editing, X.X.

Funding: This work was supported by the Special Fund for Basic Scientific Research of Central College of Chang'an University (No. 300102219308, 300102219316, 300102218413, 310821153502 and 300102218405), Innovation Talent Promotion Program-Scientific and Technological Innovation Team in Shaanxi Province (Grant No. 2017KCT-13), the Department of Science and Technology of Shaanxi Province (No. 2016 ZDJC-24).

Conflicts of Interest: The authors declare no conflict of interest.

\section{References}

1. Ding, X.; Ma, T.; Huang, X. Discrete-element contour-filling modeling method for micromechanical and macromechanical analysis of aggregate skeleton of asphalt mixture. J. Transp. Eng. Part B Pavements 2018, 145, 04018056. [CrossRef]

2. Li, J.; Zhang, J.; Qian, G.; Zheng, J.; Zhang, Y. Three-dimensional simulation of aggregate and asphalt mixture using parameterized shape and size gradation. J. Mater. Civ. Eng. 2019, 31, 04019004. [CrossRef]

3. Darjani, S.; Koplik, J.; Pauchard, V. Extracting the equation of state of lattice gases from random sequential adsorption simulations by means of the gibbs adsorption isotherm. Phys. Rev. E 2017, 96, 052803. [CrossRef] [PubMed]

4. Li, W.; Ivanov, S.; Mozaffari, S.; Shanaiah, N.; Karim, A.M. Palladium acetate trimer: Understanding its ligand-induced dissociation thermochemistry using isothermal titration calorimetry, x-ray absorption fine structure, and 31p nuclear magnetic resonance. Organometallics 2019, 38, 451-460. [CrossRef]

5. Li, R.; Wang, C.; Wang, P.; Pei, J. Preparation of a novel flow improver and its viscosity-reducing effect on bitumen. Fuel. 2016, 181, 935-941. [CrossRef]

6. Mozaffari, S.; Tchoukov, P.; Mozaffari, A.; Atias, J.; Czarnecki, J.; Nazemifard, N. Capillary driven flow in nanochannels-Application to heavy oil rheology studies. Colloids Surf. A Physicochem. Eng. Asp. 2016, 513, 178-187. [CrossRef]

7. Ali, S.I.A.; Abdulwahid, R.; Eidan, M.L.; Yusoff, N.I.M. Evaluation of moisture and ageing effects on calcium carbonite nanoparticles modified asphalt mixtures. Int. J. Eng. Res. Afr. 2018, 34, 40-47.

8. Han, N.F.; Zhou, D.J.; Tang, X.D. Effect of nano calcium carbonate and montmorillonite on properties of styrene-butadiene-styrene copolymer modified asphalt. Appl. Mech. Mater. 2011, 99-100, 1035-1038. [CrossRef]

9. Hamedi, G.H.; Nejad, F.M.; Oveisi, K. Investigating the effects of using nanomaterials on moisture damage of hma. Road Mater. Pavement Des. 2015, 16, 536-552. [CrossRef]

10. Hao, X.H.; Zhang, A.Q.; Yang, W. Study on the performance of nano calcium carbonate modified asphalt concrete ac-13. Adv. Mater. Res. 2012, 450-451, 503-507. [CrossRef] 
11. You, Z.; Mills-Beale, J.; Foley, J.M.; Roy, S.; Odegard, G.M.; Dai, Q.; Shu, W.G. Nanoclay-modified asphalt materials: Preparation and characterization. Constr. Build. Mater. 2011, 25, 1072-1078. [CrossRef]

12. Eichhorn, S.J.; Dufresne, A.; Aranguren, M.; Marcovich, N.E.; Capadona, J.R.; Rowan, S.J.; Weder, C.; Thielemans, W.; Roman, M.; Renneckar, S. Review: Current international research into cellulose nanofibres and nanocomposites. J. Mater. Sci. 2010, 45, 1. [CrossRef]

13. Li, R.; Yu, Y.; Zhou, B.; Guo, Q.; Li, M.; Pei, J. Harvesting energy from pavement based on piezoelectric effects: Fabrication and electric properties of piezoelectric vibrator. J. Renew. Sustain. Energy 2018, 10, 054701. [CrossRef]

14. Li, R.; Pei, J.; Sun, C. Effect of nano-zno with modified surface on properties of bitumen. Constr. Build. Mater. 2015, 98, 656-661. [CrossRef]

15. Sylenko, P.M.; Shlapak, A.M.; Petrovska, S.S.; Khyzhun, O.Y.; Solonin, Y.M.; Atuchin, V.V. Direct nitridation synthesis and characterization of si3n4 nanofibers. Res. Chem. Intermed. 2015, 41, 1-12. [CrossRef]

16. Liu, F.; Darjani, S.; Akhmetkhanova, N.; Maldarelli, C.; Banerjee, S.; Pauchard, V. Mixture effect on the dilatation rheology of asphaltenes-laden interfaces. Langmuir 2017, 33, 1927-1942. [CrossRef] [PubMed]

17. Mozaffari, S.; Tchoukov, P.; Atias, J.; Czarnecki, J.; Nazemifard, N. Effect of asphaltenes aggregation on rheological properties of diluted athabasca bitumen. Energy Fuels 2015, 29, 5595-5599. [CrossRef]

18. Zhang, H.G.; Hao, P.W.; Wang, X.S. Indoor research of high-modulus asphalt concrete with the added calcium sulfate whisker. Appl. Mech. Mater. 2011, 94-96, 90-94. [CrossRef]

19. Yang, Y.; Deng, Y. Mechanical properties of hybrid short fibers reinforced oil well cement by polyester fiber and calcium carbonate whisker. Constr. Build. Mater. 2018, 182, 258-272. [CrossRef]

20. Cao, M.; Xu, L.; Zhang, C. Rheology, fiber distribution and mechanical properties of calcium carbonate (caco 3) whisker reinforced cement mortar. Compos. Part A 2016, 90, 662-669. [CrossRef]

21. Li, R.; Dai, Y.; Wang, P.; Sun, C.; Pei, J. Evaluation of nano-zno dispersed state in bitumen with digital imaging processing techniques. J. Test. Eval. 2017, 46, 20160401. [CrossRef]

22. Cai, J.M.; Panteki, J. Using Calcium Carbonate Whisker in Engineered Cementitious Composites. In Proceedings of the International Conference on Fracture Mechanics of Concrete and Concrete Structures, Berkeley, CA, USA, 22-25 May 2016.

23. Xing, X.; Pei, J.; Li, R.; Tan, X. Effect and mechanism of calcium carbonate whisker on asphalt binder. Mater. Res. Express 2019, 6, 055306. [CrossRef]

24. Li, M.; Yang, Y.; Liu, M.; Guo, X.; Zhou, S. Hybrid effect of calcium carbonate whisker and carbon fiber on the mechanical properties and microstructure of oil well cement. Constr. Build. Mater. 2015, 93, 995-1002. [CrossRef]

25. Klinsky, L.M.G.; Kaloush, K.E.; Faria, V.C.; Bardini, V.S.S. Performance characteristics of fiber modified hot mix asphalt. Constr. Build. Mater. 2018, 176, 747-752. [CrossRef]

26. Fazaeli, H.; Samin, Y.; Pirnoun, A.; Dabiri, A.S. Laboratory and field evaluation of the warm fiber reinforced high performance asphalt mixtures (case study karaj-chaloos road). Constr. Build. Mater. 2016, 122, $273-283$. [CrossRef]

27. Mirabdolazimi, S.M.; Shafabakhsh, G. Rutting depth prediction of hot mix asphalts modified with forta fiber using artificial neural networks and genetic programming technique. Constr. Build. Mater. 2017, 148, 666-674. [CrossRef]

28. Jaskuła, P.; Stienss, M.; Szydłowski, C. Effect of polymer fibres reinforcement on selected properties of asphalt mixtures. Procedia Eng. 2017, 172, 441-448. [CrossRef]

29. Peter, H.M.Y.; Beaumont, W.R.; Aramid Fibers, C.H.Z. Comprehensive Composite Materials II; Elsevier: Amsterdam, The Netherlands, 2018; pp. 187-217.

30. Badeli, S.; Carter, A.; Doré, G.; Saliani, S. Evaluation of the durability and the performance of an asphalt mix involving aramid pulp fiber (apf): Complex modulus before and after freeze-thaw cycles, fatigue, and tsrst tests. Constr. Build. Mater. 2018, 174, 60-71. [CrossRef]

31. Eskandarsefat, S.; Hofko, B.; Rossi, C.O.; Sangiorgi, C. Fundamental properties of bitumen binders containing novel cellulose-based poly-functional fibres. Compos. Part B Eng. 2019, 163, 339-350. [CrossRef] 
32. D'Angelo, J.A. The relationship of the mscr test to rutting. Road Mater. Pavement 2009, 10, 61-80. [CrossRef]

33. Han, C.; Guo, T.; Nan, X.; Zhi, H.; Zhang, D. New research progress in cu-based composites. Mater. Rev. 2012, 26, 90-94.

34. Callister, W.D.; Rethwisch, D.G. Materials Science and Engineering: An Introduction; John Wiley \& Sons: New York, NY, USA, 2007; Volume 7. 